\title{
Spheramine for Treatment of Parkinson's Disease
}

\author{
Natividad P. Stover and Ray L. Watts \\ Department of Neurology, The University of Alabama at Birmingham, Birmingham, Alabama 35294
}

\begin{abstract}
Summary: Spheramine (Bayer Schering Pharma AG, Berlin, Germany) is currently being tested as a new approach for the treatment of Parkinson's disease (PD). It consists of an active component of cultured human retinal pigment epithelial (hRPE) cells, attached to an excipient part of crosslinked porcine gelatin microcarrriers. Spheramine is administered by stereotactic implantation into the striatum of PD patients and the use of immunosuppression is not required. Current pharmacologic therapies of PD are oriented to the administration of dopaminergic medications. Human RPE cells produce levodopa, and this constitutes the rationale to use Spheramine for the treatment of PD. The preclinical development of Spheramine included extensive biologic, pharmacologic, and toxicologic studies in vitro and in animal models of PD. The first clinical trial in humans evalu-
\end{abstract}

ated the safety and efficacy of Spheramine implanted in the postcommissural putamen contralateral to the most affected side in six patients with advanced PD. This open-label study demonstrated good tolerability and showed sustained motor clinical improvement. A phase II double-blind, randomized, multicenter, placebo-controlled (sham surgery) study is underway to evaluate safety, tolerability, and efficacy of Spheramine implanted bilaterally into the postcommissural putamen of patients with advanced PD. Spheramine represents a treatment approach with the potential of supplying a more continuous delivery of levodopa to the striatum in advanced PD than can be achieved with oral therapy alone. Key Words: Parkinson's disease, retinal pigment epithelial cells, neurotherapeutics, neurodegeneration, cellular therapies, cell transplantation.

\section{INTRODUCTION}

Parkinson's disease is a progressive neurodegenerative disorder, characterized by a constellation of motor and nonmotor symptoms. The cause of PD is probably multifactorial and related to both genetic and environmental factors. The pathologic diagnosis includes dopaminergic cell loss in the pars compacta of the substantia nigra and the presence of lewy bodies. ${ }^{1,2}$ The cardinal motor symptoms of PD include tremor, bradykinesia, stiffness, and postural chang$\mathrm{es}^{3}{ }^{3}$ and improve significantly with oral administration of dopaminergic medications in the majority of patients. ${ }^{4}$ Progression of the disease makes the response to oral dopaminergic medications more unpredictable, and most patients develop motor complications. Ablative surgery or deep brain stimulation may also improve the motor symptoms, as well as improving some of the complications related to pharmacologic therapy. ${ }^{5-7}$ At least some aspects of the motor complications that appear in many patients after long-term pharmacologic treatment of PD are thought to be

Address correspondence and reprint requests to: Natividad P. Stover, M.D., The University of Alabama at Birmingham, Department of Neurology, 360A Sparks Center, 1720 7th Avenue South, Birmingham, AL 35294-0017. E-mail: npstover@uab.edu. related to the pulsatile administration of the dopaminergic medications. ${ }^{8}$ Continuous systemic administration of dopaminergic agents may prevent or delay the occurrence of these disabling side effects. ${ }^{9,10}$ Numerous therapeutic clinical trials since the 1980s have attempted to address the problem of dopamine delivery and tried to develop more physiologic replacement of dopamine to treat $\mathrm{PD} .{ }^{11-13}$

To date, more than 300 patients have been treated worldwide with stereotactic implantation of dopamine-producing, allogeneic human fetal mesencephalic tissue, with conflicting results. Nonetheless, treatment has provided promising learning experiences and valuable information. ${ }^{14-27}$ Similar types of limitations were also encountered with xenotransplantation of porcine fetal mesencephalic cells. Spheramine therapy does not require the use of immunosuppression, and has advantages regarding the ethical and logistical problems associated with the use of human fetal brain tissue.

\section{PROPERTIES OF SPHERAMINE: BIOLOGICAL, PHARMACOLOGICAL, AND TECHNOLOGICAL}

Human RPE cells are support cells derived from the inner layer of the neural retina, ${ }^{28-30}$ located between the 


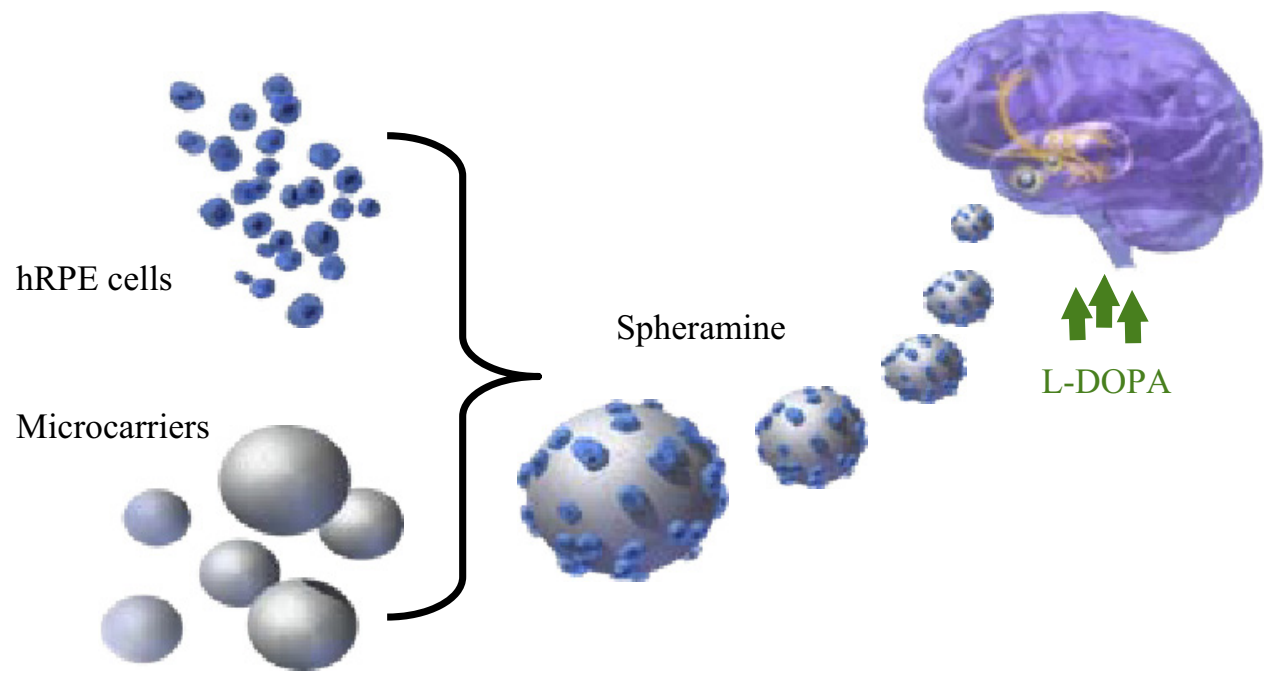

FIG. 1. Schematic depiction of Spheramine and brain implant sites.

photoreceptor and the choriocapillaris layers. These cells form tight junctions that contribute to maintaining the blood-brain barrier and provide a physical barrier to activated immune cells. The cells grow to confluence during the formation of a stable retinal structure and survive the lifetime of the individual, providing also a trophic function to the retina. Human RPE cells for transplantation are isolated from postmortem human eye tissue acquired from human eye banks; they can be expanded in tissue culture and can be stored for prolonged periods of time. ${ }^{31}$ In this way, a single donor eye can potentially treat many patients.

Melanin, the pigment present in hRPE cells, has important physiologic functions. ${ }^{32}$ Melanin is able to absorb and block light coming through the sclera, protecting the retina from light damage and improving the quality of images. Levodopa is a precursor in melanin production in hRPE cells, and during the process of melanogenesis the hRPE cells express both levodopa and small quantities of dopamine. ${ }^{33}$ In the biosynthesis of melanin, tyrosine is hydroxylated to levodopa by tyrosinase and this is converted to intermediates that polymerize to form melanin.

The immune privilege associated with the anterior chamber of the eye is thought to be related to the expression by hRPE cells of detectable levels of the Fas ligand protein, ${ }^{34,35}$ which prevents apoptosis when attached to a substance, a characteristic that may contribute to the survival of hRPE cells implanted into the brain. ${ }^{36,37}$

Human RPE cells also express retinaldehyde binding protein, cytokeratins, vesicular monoamine transporter, platelet derived growth factor, and epidermal and vascular endothelial growth factors, which contribute to support and trophic functions of hRPE cells in the retina. ${ }^{38,39}$

The technological basis of Spheramine is the combined use of hRPE cells in attachment to biologically compatible gelatin microcarriers that have a diameter of about $100 \mu \mathrm{m}$ (FIG. 1). Microcarriers have been frequently used in transplantation therapies and tissue engineering in recent years. ${ }^{40-52}$ The microcarriers present in Spheramine allow prolonged survival of the cells in the absence of immunosuppression, prevent apoptosis, and maintain the cells in a monolayer distribution, which is important in the case of hRPE cells for the process of melanization. Human RPE cells unattached to microcarriers do not survive well in the brain, and do not produce a lasting therapeutic effect in PD models. ${ }^{53}$

The tissue for the preparation of Spheramine is acquired from eye donors with negative test results for bacterial and viral infections. The isolated hRPE cells are expanded under current good manufacturing practices (cGMP) conditions and are prepared and tested for sterility. The cells are also examined for the presence of viral particles with the use of transmission electron microscopy. The microcarriers are prepared from certified porcine gelatin, processed with steam for sterilization, and prepared under cGMP conditions (FIG. 2).

The sterility of Spheramine is confirmed by Gram stain in the laboratory at the clinical site, and it is placed in Hank's Balanced Salt Solution (HBSS). The cells are tested for viability and counted before being loaded into syringes for implantation.

\section{Preclinical human studies}

Studies in vitro and in accepted animal models of PD were conducted to determine the biochemical, toxicological, and pharmacological properties of Spheramine and its components before the development of the human phase studies. ${ }^{54}$ The studies were also directed to determine the dose of Spheramine that was clinically effective in parkinsonian nonhuman primates, and these data were used to calculate the number of cells to be implanted in the human studies. 

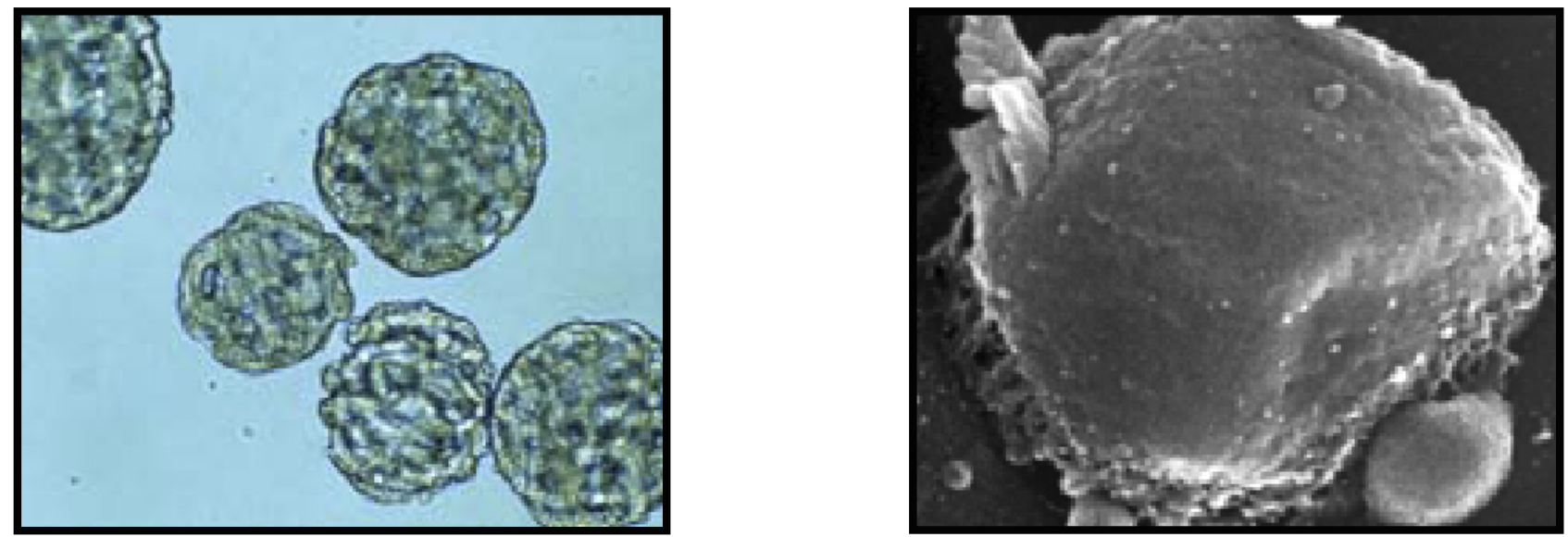

FIG. 2. Micrographs of Spheramine. Left: Microcarrier support matrix (MSM) with attached hRPE (human retinal pigment) cells (photomicrograph, 40×). Right: A single hRPE cell on an MSM (electron micrograph, 12,000×).

The preliminary efficacy of hRPE cells was determined initially in the PD animal model of unilateral 6-hydroxydopamine (6-OHDA) striatal-lesioned rats. ${ }^{55}$ The animals received approximately 1000 cells attached to 150 microcarriers in the ipsilateral lesioned striatum. The animals exhibited significant reduction in apomorphine-induced circling after the implantation, a pharmacological effect indicating an increase of dopaminergic stimulation. This effect was maintained for the duration of the 18-week study, without using immunosuppression. Implantation of hRPE cells unattached to microcarriers produced only a brief, transient effect in the animals. ${ }^{56}$

A controlled, blinded study was performed to assess the effect of intrastriatal implantation of hRPE cells on gelatin microcarriers in MPTP-induced hemiparkinsonian Maccaca mulatta monkeys. The animals that were implanted with approximately 250,000 hRPE cells on gelatin microcarriers over five sites in the lesioned striatum had statistically significant motor improvement at 12 months after implantation, compared with control animals. The animals implanted with a low dose of cells (50,000 with microcarriers) or with microcarriers alone did not show significant improvement of symptoms. ${ }^{53}$

As part of the toxicology studies, the Ames test Salmonella typhimurium reverse mutation assay, ${ }^{57,58}$ an accepted test that studies mutagenic effects, showed no mutations when used with Spheramine. A toxicological study with intracranial implantation of gelatin microcarriers or Spheramine was done in M. fascicularis monkeys to estimate the maximally tolerated total dose of Spheramine or of the gelatin microcarriers alone. To test the related mortality or body weight effects, gelatin microcarrier beads were implanted intracranially in M. fascicularis; histopathological examination of the brain in these animals showed only mild astroglial cell proliferation and inflammation, with no evidence of granulomatous or immune-mediated reactions.

\section{HUMAN STUDIES}

\section{Phase I study}

The first study in humans evaluated primarily the safety and tolerability of Spheramine in an open-label, single-center, pilot study in six patients with advanced PD. The exploratory evaluation of efficacy focused on motor disability. All the patients had bilateral but asymmetric PD, moderate to severe motor symptoms, motor fluctuations, and dyskinesias of varying degrees; all were levodopa responders. The patients were placed on optimal antiparkinsonian medications and the doses were maintained stable for at least 3 months before the surgery. The patients had baseline evaluations 1 month before surgery in the off state as practically defined-that is, in the morning after at least 12 hours overnight without taking medications. All the patients had normal findings on magnetic resonance imaging (MRI) prior to surgery.

The mean age of the patients was 52 years (40-70), and they had a mean PD duration of 10 years. The Hoehn and Yahr stages were 3-4 in the off state and 2-3 during the on state.

Surgery was done using MRI stereotactic guidance to target the postcommissural putamen. A burr hole was made anterior to the coronal suture with the patient under general anesthesia and in the supine position. A total of approximately $325,000 \mathrm{hRPE}$ cells on gelatin microcarriers in $250 \mu \mathrm{L}$ were implanted unilaterally in five tracts in the postcommisural putamen, contralateral to the patient's more affected side. The tracts were spaced $5 \mathrm{~mm}$ apart, and in each tract there were two deposits of $25 \mu \mathrm{L}$ separated by 5 to $10 \mathrm{~mm}$ in each target. The patients were taken to a recovery room and then transferred to a hospital bed and discharged within 3 days, after a brain MRI confirmed accurate placement of the implants. ${ }^{59}$ 


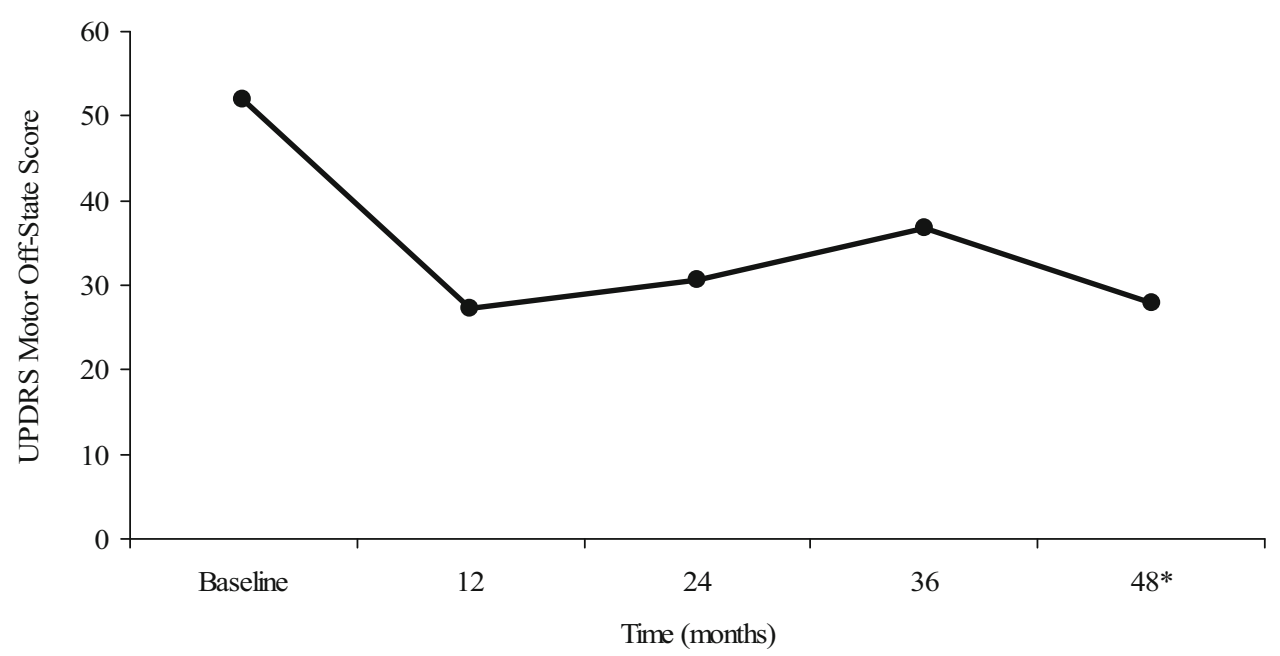

FIG. 3. Mean changes of UPDRS (Unified Parkinson's Disease Rating Scale) motor off scores ( $\left.{ }^{*} n=5\right)$.

The safety and tolerability evaluations consisted of clinical and neurological examinations, recording of side effects, vital signs, and standard laboratory studies at 1 , $3,6,12,24,36$, and 48 months after surgery, as well as periodic brain MRI and neuropsychological evaluations. ${ }^{60}$ The patients tolerated the implantation well, and there were no serious adverse events related to the treatment. One patient had a small hemorrhage $(4 \times 7 \mathrm{~mm})$ that was asymptomatic immediately after the surgery and subsequently resolved. One patient had an episode of depression with suicidal ideation at 14 months after surgery that required admission to the hospital; this was treated medically and improved in the subsequent weeks.

The most frequent side effect was transient headache immediately after the surgery in the six patients, which resolved spontaneously in 1 to 2 weeks The adverse events that were considered as possibly or probably related to the treatment were transient increases in peakdose dyskinesias (in four of the six patients), which were mild, and the appearance of visual hallucinations without previous episodes (in three of the six patients). Both side effects resolved after reducing the antiparkinsonian medications. One patient reported increased freezing episodes at 7 months after implantation. There were no significant changes in laboratory assessments. ${ }^{61}$

The exploratory primary efficacy outcome measure was the change from baseline in the Unified Parkinson Disease Rating Scale (UPDRS) during the practically defined off state. The results showed a clinically and statistically significant improvement from baseline in the UPDRS motor off state score in all six patients. The mean improvement was a $48 \%$ reduction of the off state in the UPDRS motor disability score at 12 months, which was sustained through 24 months (with an average improvement of $41 \%$ ). This improvement was maintained at $43 \%$ at 48 months in five of the six patients; the sixth patient refused to be off the PD medications overnight.
The UPDRS motor off state score improved from mean ( $\pm \mathrm{SD}$ ) of $52 \pm 9$ at baseline to $27 \pm 7$ at 12 months, 31 \pm 7 at 24 months, and $28 \pm 5$ at 48 months (FIG. 3).

The clinical motor improvement was more evident contralateral to the implanted striatum. On state time, measured using patient diaries, ${ }^{62}$ increased from $44 \%$ of the awake day at baseline to $55 \%$ at 12 months, $65 \%$ at 24 months, and 53\% at 48 months after surgery. The off state duration of the awake day decreased from $41 \%$ at baseline to $30 \%$ at 12 months, $28 \%$ at 24 months, and $35 \%$ at 48 months ( $n=5$ patients) (FIG. 4). Total UPDRS scores decreased from $118 \pm 14$ mean at baseline to $69 \pm 10$ at 48 months. There was no increased on state time with dyskinesias, and no off state dyskinesias $^{63}$ were observed. The section of the UPDRS regarding mentation, behavior, and mood was maintained stable during the 4 years of follow-up. Scores on the PD Quality of Life Questionnaire (PDQ-39) ${ }^{64-66}$ improved from a mean of $42 \pm 11$ at baseline to $26 \pm 12$ at 12 and at 24 months and to $29 \pm 20$ at 48 months (Table 1).

\section{Phase II study}

Based on the results of the human phase I clinical trial, a phase II study was initiated and the surgeries have just been completed. This trial was a double-blind, randomized, multicenter, placebo (sham-surgery) controlled study of the safety, tolerability, and efficacy of Spheramine implanted bilaterally into the postcommissural putamen of patients with advanced PD. To maintain the blind, the surgical procedures were performed by a neurosurgeon located at a medical center geographically separated from where the patient was evaluated. The study was designed to include three cohorts. In the first group there were 12 patients, with 6 assigned to active treatment and 6 to sham surgery. The second cohort comprised 24 patients, and a new review of the accumu- 


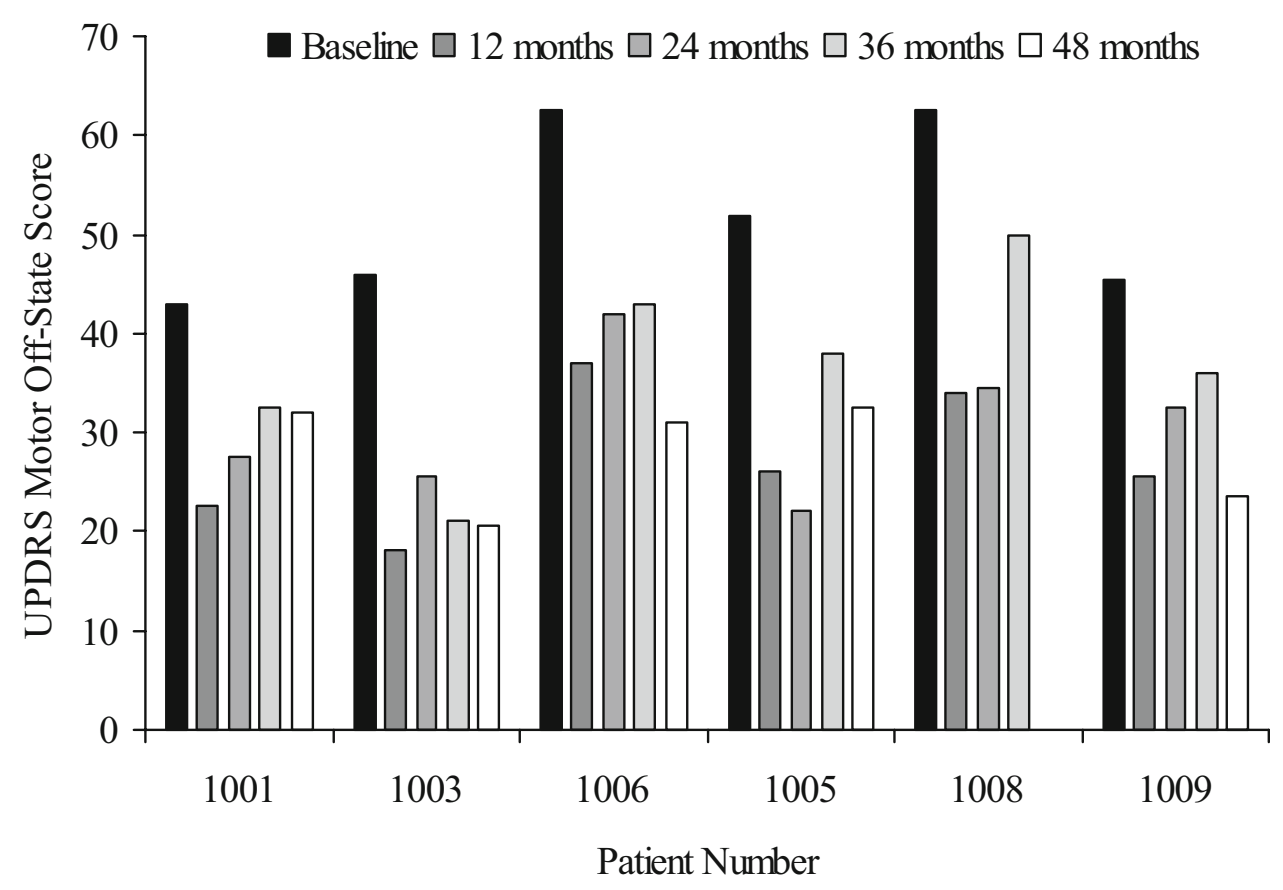

FIG. 4. Mean changes of UPDRS (Unified Parkinson's Disease Rating Scale) (Patient 1008: data for 36 months).

lated safety data was done before proceeding to the third cohort. A total of 71 patients underwent surgery.

The primary efficacy endpoint of the study was the change in the UPDRS motor subscore during the off state after 12 months, compared with baseline. Secondary endpoints included the change in total UPDRS scores, UPDRS motor subscores during the on state, UPDRS activities of daily living scores, quality of life scores (PDQ-39), and evaluation of dyskinesias.

The candidates were evaluated and their medications optimized 3 months before the surgery. The inclusion criteria required that the patients have disease duration of more than 5 years, be in the age range from 30 to 70 years, have bilateral disease, and have insufficient symptom control or intolerable side effects with best medical treatment. Patients were excluded from the study if they had PD with only tremor-based symptomatology, severe dyskinesias, significant psychiatric or cognitive symptoms, or severe or uncontrolled systemic disease. The patients were required to have at least 33\% improvement in the UPDRS motor score between the practically defined off and on state at the screening visit, and the scores had to be between 38-70 points. Also, patients were required to have unequivocal clinical on and off periods.

The patients were randomized to receive either bilateral stereotactic implantation of Spheramine into the postcommissural putamen $(325,000$ cells per side) or sham surgery. The patients were evaluated every 2 weeks during the first month after surgery, then monthly for 3 months, and then every 3 months thereafter, up to 2 years. The selection of the dose of 325,000 cells was based on the animal studies, as well as the dose used in the open-label human clinical study. The surgical team in charge was unblinded only for the patients on whom they

TABLE 1. Exploratory Efficacy Outcomes from the Phase I Pilot Study

\begin{tabular}{lcccc}
\hline \multicolumn{1}{c}{ Characteristic } & Baseline & 12 mo & 24 mo & 48 mo \\
\hline UPDRS motor score OFF, mean \pm SD & $52 \pm 9$ & $27 \pm 7$ & $31 \pm 7$ & $28 \pm 5$ \\
UPDRS motor OFF improvement, $\%$ & N/A & 48 & 41 & 43 \\
Time ON state, $\%$ & 41 & 55 & 65 & 53 \\
Time OFF state, $\%$ & $118 \pm 14$ & $67.4 \pm 18$ & $75.2 \pm 24.5$ & $69 \pm 10$ \\
Total UPDRS score, mean \pm SD & 14 & 15 & 7 & 12 \\
Time ON state with dyskinesias, $\%$ & $24 \pm 11$ & $15 \pm 6$ & $17 \pm 7$ & $20 \pm 9$ \\
UPDRS ADL score, OFF, mean \pm SD & $42 \pm 11$ & $26 \pm 12$ & $26 \pm 12$ & $29 \pm 20$ \\
PDQ-39 total score, mean \pm SD &
\end{tabular}

The Phase I Pilot Study involved six patients: mean age, 52 years (range, 40-70), mean PD duration, 10 years; Hoehn and Yahr stages 3-4 in the off state and 2-3 in the on state.

$\mathrm{ADL}=$ activities of daily living; N/A = not applicable; PDQ-39 = PD Quality of Life Questionnaire; SD = standard deviation; UPDRS $=$ Unified Parkinson's Disease Rating Scale. 
operated. The treating neurologist, UPDRS rater, and all other staff remained blinded. The same independent rater evaluated each patient during all of the visits.

The safety evaluations included physical and neurological examinations, vital signs, adverse events, electrocardiography, laboratory parameters and periodic brain MRI and neuropsychological assessments. The regimen of medications was maintained stable for at least the first year, unless medically necessary to treat side effects or in case of substantial deterioration of the patient's condition.

All patients had stereotactic frame placement, followed by brain MRI. In the operating room, the patients received anesthesia appropriate to make them unaware of the activities. The patients were randomized to Spheramine or placebo treatment. The patients randomized to Spheramine had bilateral scalp incisions, with burr holes placed in the calvaria and opening of the dura. A total of $325,000 \mathrm{hRPE}$ cells in a volume of $250 \mu \mathrm{L}$ distributed along five needle tracts spaced about $5 \mathrm{~mm}$ apart were stereotactically implanted into each postcommissural putamen. Each tract had two deposits of $25 \mu \mathrm{L}$ of Spheramine suspension placed approximately $5-10 \mathrm{~mm}$ apart along the linear tract $(65,000 \mathrm{hRPE}$ cells per tract). The sham surgery control patients had bilateral scalp incisions, with burr holes placed in the outer table of the calvaria but without opening of the dura. The duration of the sham surgery was similar to that of the treatment surgery.

A placebo-controlled, double blind study was chosen to provide an unbiased evaluation of the efficacy and safety of Spheramine in PD patients with moderate to advanced disease. ${ }^{67,68}$ The patients treated with placebo in this phase II trial will be eligible to receive Spheramine if this study demonstrates satisfactory efficacy and safety after the data are analyzed. Also, phase III studies will follow.

\section{CONCLUSION}

Spheramine is currently an experimental approach for the treatment of PD and the preclinical and open-label human studies show promise worthy of further investigation. Currently, it is postulated that the ability of hRPE cells to produce levodopa in the biosynthetic pathway for melanogenesis may serve as the rationale for a therapeutic effect, but a role of trophic factors cannot be excluded.

A double-blind, controlled phase II study in advanced PD patients is currently underway, and data from this study will be available for analysis within 12 to 18 months. If this study demonstrates acceptable tolerability, safety, and efficacy then a pivotal phase III trial will be warranted.
Acknowledgments: We would like to thank our colleagues at Emory University and the University of Alabama at Birmingham who assisted us with these studies. Research reported in this article was funded by Titan Pharmaceuticals, Schering AG, Bayer Healthcare, and the National Institutes of Health. R.L.W. has served as a consultant and received honoraria from Titan Pharmaceuticals, Schering AG, and Bayer Healthcare.

\section{REFERENCES}

1. Wainer BH, Stover NP. Parkinson's disease: neuropathology. In: Watts RL, Koller WC, editors. Movement disorders: neurologic principles and practice. 2nd ed. New York: McGraw-Hill, 2004: 327-336.

2. Braak H, Del Tredici K, Rüb U, de Vos RA, Jansen Steur EN, Braak E. Staging of brain pathology related to sporadic Parkinson's disease. Neurobiol Aging 2003;24:197-211.

3. Rajput AH. Clinical features and natural history of Parkinson's disease (special consideration of aging). In: Calne DB, editor. Neurodegenerative diseases. Philadelphia: W.B. Saunders, 1994: 555-572.

4. Poewe W, Granata R, Geser F. Pharmacologic treatment of Parkinson's disease. In: Movement disorders: neurologic principles and practice. 2nd ed. New York: McGraw-Hill, 2004:247-271.

5. Lang AE, Lozano AM, Montgomery E, Duff J, Tasker R, Hutchinson W. Posteroventral medial pallidotomy in advanced Parkinson's disease. N Engl J Med 1997;337:1036-1042.

6. Kumar R, Lozano AM, Kim YJ, et al. Double-blind evaluation of subthalamic nucleus deep brain stimulator in advanced Parkinson's disease. Neurology 1998;51:850-855.

7. The Deep Brain Stimulation for Parkinson's Disease Study Group. Deep-brain stimulation of the subthalamic nucleus or the pars interna of the globus pallidus in Parkinson's disease. N Engl J Med 2001;345:956-963.

8. Chase TN, Juncos J, Serrati C, Fabbrini G, Bruno G. Fluctuation in response to chronic levodopa therapy: pathogenetic and therapeutic considerations. Adv Neurol 1987;45:477-480.

9. Mouradian MM, Juncos JL, Fabbrini G, Schlegel J, Bartko JJ, Chase TN. Motor fluctuations in Parkinson's disease: central pathophysiologic mechanism, Part II. Ann Neurol 1988;24:372378.

10. Chase TN. The significance of continuous dopaminergic stimulation in the treatment of Parkinson's disease. Drugs 1998;55 Suppl $1: 1-9$.

11. Freeman TB, Olanow CW, Hauser RA, et al. Bilateral fetal nigral transplantation into the postcommissural putamen in Parkinson's disease. Ann Neurol 1995;38:379-388.

12. Watts RL, Subramanian T, Freeman A, et al. Effects of stereotaxic intrastriatal cografts of autologous adrenal medulla and peripheral nerve in Parkinson's disease: two-year follow-up study. Exp Neurol 1997;147:510-517.

13. Freeman TB, Widner H. Cell transplantation for neurological disorders: towards reconstruction of the human central nervous system. Totowa, NJ: Humana Press, 1998.

14. Perlow MJ, Freed WJ, Hoffer BJ, Seiger A, Olson L, Wyatt RJ. Brain grafts reduce motor abnormalities produced by destruction of the nigrostriatal dopamine system. Science 1979;204:643-647.

15. Fahn S. Double-blind controlled trial of embryonic dopaminergic tissue transplants in advanced Parkinson's disease. Mov Disord 2000;15:M114 (abstract).

16. Watts RL, Freeman TB, Hauser RA, et al. A double-blind, randomized, controlled, multicenter clinical trial of the safety and efficacy of stereotaxic intrastriatal implantation of fetal porcine ventral mesencephalic tissue (Neurocell-PD ${ }^{\mathrm{TM}}$ ) versus imitation surgery in patients with Parkinson's disease. Parkinsonism Relat Disord 2001;7 Suppl 1:S87 (abstract).

17. Clarkson ED. Fetal tissue transplantation for patients with Parkinson's disease: a database of published clinical results. Drugs Aging 2001;18:773-785.

18. Hagell P, Piccini P, Björklund A, et al. Dyskinesias following neural transplantation in Parkinson's disease. Nat Neurosci 2002; 5:627-628. 
19. Olanow CW, Goetz CG, Kordower JH, et al. A double-blind controlled trial of bilateral fetal nigral transplantation in Parkinson's disease. Ann Neurol 2004;54:403-414.

20. Kirik D, Georgievska B, Björklund A. Localized striatal delivery of GDNF as a treatment for Parkinson disease. Nat Neurosci 2004;7:105-110.

21. Slevin JT, Gerhardt GA, Smith CD, Gash DM, Kryscio R, Young B. Improvement of bilateral motor functions in patients with Parkinson disease through the unilateral intraputaminal infusion of glial cell line-derived neurotrophic factor. J Neurosurg 2005;102: 216-222.

22. Björklund A, Stenevi U. Reconstruction of the nigrostriatal dopamine pathway by intracerebral nigral transplants. Brain Res 1979; 177:555-560.

23. Kordower J, Freeman TB, Snow BJ, et al. Neuropathological evidence of graft survival and striatal reinnervation after the transplantation of fetal mesencephalic tissue in a patient with Parkinson's disease. N Engl J Med 1995;332:1118-1124.

24. Kordower JH, Rosenstein JM, Collier TJ, et al. Functional fetal nigral grafts in a patient with Parkinson's disease: chemoanatomic, ultrastructural, and metabolic studies. J Comp Neurol 1996;24: 203-230.

25. Subramanian T. Cell transplantation for the treatment of Parkinson's disease. Semin Neurol 2001;21:103-115.

26. Freed CR, Greene PE, Breeze RE, et al. Transplantation of embryonic dopamine neurons for severe Parkinson's disease. N Engl J Med 2001;344:710-719.

27. Gill SS, Patel NK, Hotton GR, et al. Direct brain infusion of glial cell line-derived neurotrophic factor in Parkinson's disease. Nat Med 2003;9:589-595.

28. Burnside B, Bost-Usinger L. The retinal pigment epithelial cytoskeleton. In: Marmor MF, Wolfensberger TJ, editors. The retinal pigment epithelium: function and disease. New York: Oxford University Press, 1998:41-67.

29. Schraermeyer U, Heimann K. Current understanding on the role of retinal pigment epithelium and its pigmentation. Pigment Cell Res 1999;12:219-236.

30. Hageman GS, Kuehn MH. Biology of the interphotoreceptor matrix-retinal pigment epithelium-retina interface. In: Marmor MF, Wolfensberger TJ, editors. The retinal pigment epithelium: function and disease. New York: Oxford University Press, 1998:361391.

31. Cherksey BD, inventor; New York University (New York, NY), assignee. Method for increasing the viability of cells which are administered to the brain or spinal cord. US patent 5,618,531. April 8, 1997.

32. Boulton M. Melanin and the retinal pigment epithelium. In: Marmor MF, Wolfensberger TJ, editors. The retinal pigment epithelium: function and disease. New York: Oxford University Press, 1998:68-85.

33. Pawelek JM, Körner AM. The biosynthesis of mammalian melanin. Am Sci 1982;70:136-145.

34. Jørgensen A, Wiencke AK, la Cour M, et al. Human retinal pigment epithelial cell-induced apoptosis in activated $\mathrm{T}$ cells. Invest Ophthalmol Vis Sci 1998;39:1590-1599.

35. Griffith TS, Brunner T, Fletcher SM, Green DR, Ferguson TA. Fas ligand-induced apoptosis as a mechanism of immune privilege. Science 1995;270:1189-1192.

36. Wenkel H, Streilein JW. Analysis of immune deviation elicited by antigens injected into the subretinal space. Invest Ophthalmol Vis Sci 1998;39:1823-1834.

37. Liversidge J, Forrester JV. Regulation of immune responses by the retinal pigment epithelium. In: Marmor MF, Wolfensberger TJ, editors. The retinal pigment epithelium: function and disease. New York: Oxford University Press, 1998:511-527.

38. Campochiaro PA. Cytokine production by retinal pigmented epithelial cells. Int Rev Cytol 1993;146:75-82.

39. Campochiaro PA. Growth factors in the retinal pigment epithelium and retina. In: Marmor MF, Wolfensberger TJ, editors. The retinal pigment epithelium: function and disease. New York: Oxford University Press, 1998:459-477.

40. Wissemann KW, Jacobson BS. Pure gelatin microcarriers: synthe- sis and use in cell attachment and growth of fibroblast and endothelial cells. In Vitro Cell Dev Biol 1985;21:391-401.

41. Bhatt NS, Newsome DA, Fenech T, et al. Experimental transplantation of human retinal pigment epithelial cells on collagen substrates. Am J Ophthalmol 1994;117:214-221.

42. Cherksey BD. Microcarrier pre-adhesion enhances long term survival of adults cells implanted into the mammalian brain. Exp Neurol 1994;129:S18 (abstract).

43. Cherksey BD, Sapirstein VS, Geraci AL. Adrenal chromaffin cells on microcarriers exhibit enhanced long-term functional effects when implanted into the mammalian brain. Neuroscience 1996;75: 657-664.

44. Potter BM, Kidwell W, Cornfeldt M. Functional effects of intrastriatal hRPE grafts in hemiparkinsonian rats is enhanced by adhering to microcarriers. Soc Neurosci Abstr 1997;778.10 (abstract).

45. Tezel TH, Del Priore LV. Reattachment to a substrate prevents apoptosis of human retinal pigment epithelium. Graefes Arch Clin Exp Ophthalmol 1997;235:41-47.

46. Saporta S, Borlongan C, Moore J, et al. Microcarrier enhanced survival of human and rat fetal ventral mesencephalon cells implanted in the rat striatum. Cell Transplant 1997;6:579-584.

47. Cherksey BD, inventor; The New York University Medical Center (New York, NY), assignee. Method for transplanting cells into the brain and therapeutic uses therefor. US patent 5,750,103. May 12, 1998.

48. Tatard VM, Venier-Julienne MC, Saulnier P, et al. Pharmacologically active microcarriers: a tool for cell therapy. Biomaterials 2005;3727-3737.

49. Liu JY, Hafner J, Dragieva G, Burg G. High yields of autologous living dermal equivalents using porcine gelatin microbeads as microcarriers for autologous fibroblasts. Cell Transplant 2006;15: $445-451$

50. Tielens S, Declercq H, Gorski T, Lippens E, Schacht E, Cornelissen M. Gelatin-based microcarriers as embryonic stem cell delivery system in bone tissue engineering: an in-vitro study. Biomacromolecules 2007;8:825-832.

51. Pfeffer B. Improved methodology for cell culture of human and monkey retinal pigment epithelium. Prog Retina Res 1991;10:251291.

52. Borlongan CV, Saporta S, Sanberg PR. Intrastriatal transplantation of rat adrenal chromaffin cells seeded on microcarrier beads promote long-term functional recovery in hemiparkinsonian rats [Erratum in: Exp Neurol 1998;154:259]. Exp Neurol 1998;154:203214.

53. Subramanian T, Bakay RAE, Cornfeldt ME, Watts RL. Blinded placebo-controlled trial to assess the effects of striatal transplantation of human retinal pigmented epithelial cells attached to microcarriers (hRPE-M) in parkinsonian monkeys. Parkinsonism Relat Disord 1999;5:S111 (abstract).

54. Watts RL, Raiser CD, Stover NP, et al. Stereotaxic intrastriatal implantation of human retinal pigment epithelial (hRPE) cells attached to gelatin microcarriers: a potential new cell therapy for Parkinson's disease. J Neural Transm Suppl 2003;65:215-227.

55. Ungerstedt U, Arbuthnott GW. Quantitative recording of rotational behavior in rats after 6-hydroxy-dopamine lesions of the nigrostriatal dopamine system. Brain Res 1970;24:485-493.

56. Subramanian T, Marchionini D, Potter EM, Cornfeldt ML. Striatal xenotransplantation of human retinal pigment epithelial cells attached to microcarriers in hemiparkinsonian rats ameliorates behavioral deficits without provoking a host immune response. Cell Transplant 2002;11:207-214.

57. Ames B, McCann J, Yamasaki E. Methods for detecting carcinogens and mutagens with the Salmonella/mammalian-microsome mutagenicity test. Mutat Res 1975;31:347-364.

58. Maron D, Ames B. Revised methods for the Salmonella mutagenicity test. Mutat Res 1983;113:173-215.

59. Bakay RAE, Raiser CD, Subramanian T, et al. Implantation of Spheramine ${ }^{\circledR}$ in advanced Parkinson's disease. Front Biosci 2004; 9:592-602.

60. Langston JW, Widner H, Goetz CG, et al. Core assessment program for intracerebral transplantations (CAPIT). Mov Disord 1992;7:2-13. 
61. Stover NP, Bakay RAE, Subramanian T, et al. Intrastriatal implantation of human retinal pigment epithelial cells attached to microcarriers in advanced Parkinson disease. Arch Neurol 2005; 62:1833-1837.

62. Hauser RA, Friedlander J, Zesiewicz TA, et al. A home diary to assess functional status in patients with Parkinson's disease with motor fluctuations and dyskinesias. Clin Neuropharmacol 2000;23: $75-81$.

63. Goetz CG, Stebbins GT, Shale HM, et al. Utility of an objective dyskinesia rating scale for Parkinson's disease: inter- and intrarater reliability assessment. Mov Disord 1994;9:390-394.

64. Peto V, Jenkinson C, Fitzpatrick R, Greenhall R. The development and validation of a short measure of functioning and well being for individuals with Parkinson's disease. Qual Life Res 1995;4:241-248.
65. Jenkinson C, Fitzpatrick R, Peto V, Greenhall R, Hyman N. The Parkinson's Disease Questionnaire (PDQ-39): development and validation of a Parkinson's disease summary index score. Age Ageing 1997;26:353-357.

66. Bushnell DM, Martin ML. Quality of life and Parkinson's disease: translation and validation of the US Parkinson's Disease Questionnaire (PDQ-39). Qual Life Res 1999;8:345-350.

67. Shetty N, Friedman JH, Kieburtz K, Marshall FJ, Oakes D; Parkinson Study Group. The placebo response in Parkinson's disease. Clin Neuropharmacol 1999;22:207-212.

68. Goetz CG, Leurgans S, Raman R, Stebbins GT. Objective changes in motor function during placebo treatment in PD. Neurology 2000;54:710-714. 